\title{
Application of Real-time Compensation of Cutting Force Induced Error on CNC Machine Tools
}

\author{
Chenggao Ren ${ }^{1, a}$, Xiaolong Shen ${ }^{1, b}$ \\ ${ }^{1}$ Hunan Industry Polytechnic, Changsha, 410208, China \\ arenchenggao@yeah.net, bShenXL64@126.com
}

Keywords: CNC machine tool, Cutting force induced error, Real-time compensation, Machining precision.

\begin{abstract}
Deformations due to the impact of cutting force are factual and a principal source of error, the cutting force induced errors cannot be disregards and mere controlled by technical skill. In this paper, based on the compensatory circuit and model the errors are determined and compensated in real-time. An intelligent compensation is developed based on Neural Network Programming and mechanistic modeling, It is progressively accomplished through the normal working life and referenced to the indirect monitoring compensation system. it shows that the implementation of the system was found to significantly reduce the cutting force induced error.
\end{abstract}

\section{Introduction}

Machine tool manufacturers and researchers are constantly been improving the accuracy and precision of the machine tools. Particularly, great improvements have been enhanced for machine tools inaccuracy caused by thermal deformations. Consequently, cutting force induced errors have become more dominating on the remaining account of overall machine errors [1-2].

Hence cutting force induced errors have become the main focus for improvement of machine accuracy and machining efficiency. Researchers have tackled the improving accuracy based on the two basic methods namely: error prevention and error compensation. The former is founded on the strategy of careful design as a means to improving the stiffness of the subject machine tool [3-5]. While the later is adopts the software method of canceling errors during their process of manifestation.

The subject machine tool is VC600 CNC milling machine (shown in fig.1) was selected for the CFIE compensation procedure. VC600 CNC milling machine is a structurally weak implying that it is very sensitive to external forces. The preparatory study on the static loading of this machine showed that its spindle, $\mathrm{X}, \mathrm{Y}$, and $\mathrm{Z}$ slides and ballscrew systems deform tremendously under the influence of cutting force. The maximum deformation registered was for the $\mathrm{X}$ transmission system with was about $11 \mu \mathrm{m}$ for the force of $1.8 \mathrm{kN}$ [6]. This showed that the CFIE can caused tremendous influence on its accuracy of VC600 CNC milling machine.

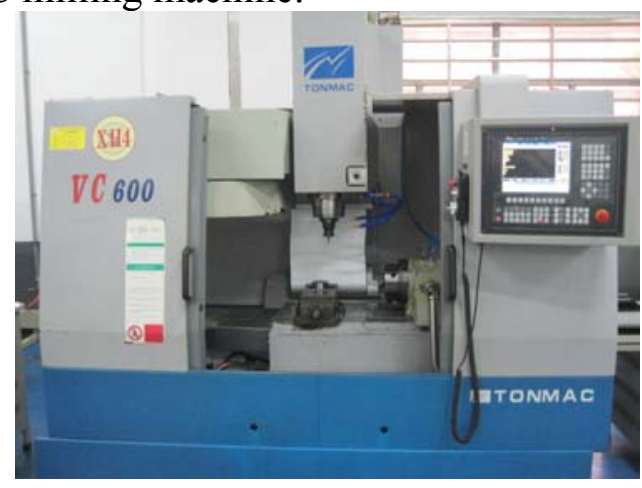

Fig. 1 VC600 CNC milling machine tool

\section{Implementation of the CFIE compensation system}


The systems based on motor current monitoring has been developed by combining the dedicated compensating board and PLC in conjunction with the existing controller of VC600 Milling machine [7-8]. The overall combination of hardware, software and mathematical model constitutes what is called the compensation control systems as demonstrated in fig. 2 .

During the machining process the calibrated Hall Effect sensors are engaged and their values are interpreted by the model to generate the equivalent compensation values. Through the SMC and PMC in conjunction with the ladder program, the values are effectively sent into the CNC controller. Finally the controller reads the compensation signals for the three axes from the compensator memory and shifts the origins of the $\mathrm{X}, \mathrm{Y}$, and $\mathrm{Z}$ axes to implement the compensation accordingly.

The Error signal is read online through current sensors and the data is sent through the B2 I/O card through PMC PCB and then Master PCB to the CNC controller [9]. The speed and positions of slides are determined by the quadrant signals of the speed and position decoder of machine tool. Finally these signals are combination of the machining program and the feedback signal gives improved rightful positions of the cutting tools in real time.

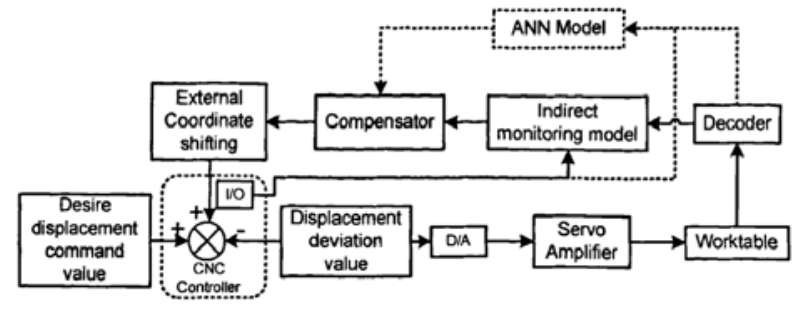

Fig. 2 Compensation by external coordinate shift

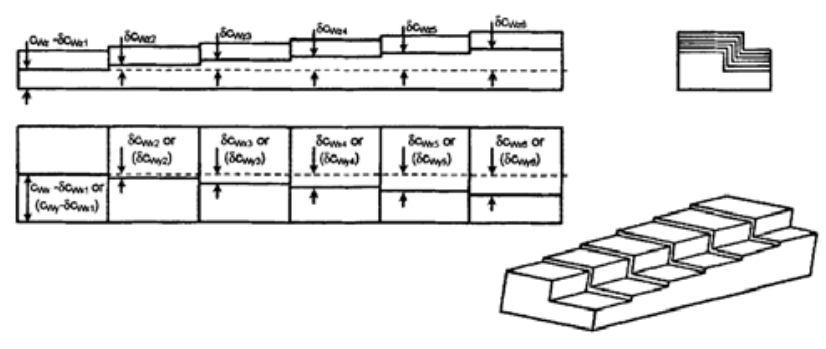

Fig. 3 Test block for post inspection after experiment 1

\section{Evaluation of the CFIE compensation system}

Evaluation procedure 1 (Indirect prediction model). Two set of Cast iron and carbon steel test blocks as shown in fig. 3 is subjected to machining by an end-milling tool of diameter $2 \mathrm{~cm}$ fitted with Tungsten Carbide inserts. In this case the test blocks are prepared in such way that such that machining them without change of depth of cut instructions still achieve change of depth phenomenon. This is achieved by arranging a workpiece with steps each with a difference in height which will give a variation in the depth of cut, Hence successive variation of CFIE for each step as demonstrated in fig.3. This means that in this workpiece is machine without change of position for $\mathrm{Z}$ direction, still a change of depth is experienced. Finally of the two prepared set of workpieces, one set was machined with the compensation engaged, while the other one was not.

The technical specifications of milling tool and workpiece are as follows:

Workpiece material: Cold Cast steel;

Milling tool diameter (equal to width of milling, $a_{c}$ ) $d_{e}=20 \mathrm{~mm}$;

Milling tool material: Tungsten Carbide (10\% TC);

Tool angles: rake angle $\gamma_{0}=-5^{0} ; \mathrm{K}_{\mathrm{r}}=60^{\circ}$;

Number of teeth: 4;

Feed per tooth $\left(\mathrm{f}_{\mathrm{z}}\right)=0.16 \mathrm{~mm} / \mathrm{z}$;

Cutting speed $\left(\mathrm{v}_{\mathrm{c}}\right)=63 \mathrm{~m} / \mathrm{min}$.

The two block where inspected by Non-contact Coordinate Measuring Machine (Mututoyo BRIGHTSTRATO 776) for $\mathrm{x}, \mathrm{y}$, and positions.

The graphical representation of the findings are represented in table 1 and illustrated as shown table 1 and demonstrated in fig. 4 clear showing tremendous improvement of accuracies by engaging of the compensation system for different depth of cut. Measurements of the errors induced by the change of depth of cut caused by the variation of step height were taken in the investigation for the CFIE in the $\mathrm{X}, \mathrm{Y}$ and $\mathrm{Z}$ directions. The findings are shown in fig.4, which includes the depth of cut and the corresponding measure with and without engaging the CFIE compensation system. 
Whereby $\mathrm{dx}$, dy and $\mathrm{dz}$ are workpiece errors without compensation for $\mathrm{x}, \mathrm{y}$ and $\mathrm{z}$ directions respectively; drx, dry and drz are workpiece errors with compensation for $\mathrm{x}, \mathrm{y}$ and $\mathrm{z}$ directions respectively; DoF is the Depth of Cut.

According to the analysis of the results from the two procedures demonstrated that the real CFIE compensation system respond to the variations of depth of cut (representing the variation of cutting force). It also proved the correctness of the mathematical model since the magnitudes of errors measured closely tallied with the expected values. The accuracy of machined workpiece demonstrated tremendous improvement.

Table 1. Evaluation results for procedure 1

\begin{tabular}{|c|c|c|c|c|c|c|}
\hline Step name & $\mathrm{SP}_{\mathbf{x} 1}$ & $\mathrm{SP}_{\mathrm{x} 2}$ & $\mathrm{SP}_{\mathrm{x} 3}$ & $\mathrm{SP}_{\mathrm{x} 4}$ & $\mathrm{SP}_{\mathrm{x} 5}$ & $\mathrm{SP}_{\mathrm{x} 6}$ \\
\hline Depth of Cut $\left(a_{p}\right) / \mathrm{mm}$ & 1.00 & 1.50 & 2.00 & 2.50 & 3.00 & 3.50 \\
\hline Error in $\mathbf{X}$ direction & $\delta c_{w 11}$ & $\delta \mathbf{c}_{\mathrm{w} \times 2}$ & $\delta \mathbf{c}_{\mathbf{W} \times 3}$ & $\delta c_{w_{x 4}}$ & $\delta \mathbf{c}_{w_{x s}}$ & $\delta c_{w_{x 6}}$ \\
\hline When compensation system not engaged & 3.28 & 5.03 & 4.78 & 6.97 & 8.50 & 8.60 \\
\hline When compensation system engaged & 1.57 & 2.80 & 3.56 & 3.43 & 4.83 & 4.65 \\
\hline Error in $\mathbf{Y}$ direction & $\delta \mathbf{c}_{\mathbf{w y 1}}$ & $\delta \mathbf{c}_{\mathrm{w} y 2}$ & $\delta \mathbf{c}_{w y 3}$ & $\delta c_{w y 4}$ & $\delta \mathbf{c}_{\text {wys }}$ & $\delta c_{w y 6}$ \\
\hline When compensation system not engaged & 3.60 & 3.85 & 4.52 & 5.68 & 6.74 & 6.80 \\
\hline When compensation system engaged & 1.91 & 2.47 & 2.49 & 3.31 & 3.23 & 3.47 \\
\hline Error in $\mathbf{Z}$ direction & $\delta \mathbf{c}_{\mathbf{w}_{21}}$ & $\delta \mathbf{c}_{\mathrm{w}_{22}}$ & $\delta \mathbf{c}_{\mathbf{W} z}$ & $\delta \mathbf{c}_{\mathbf{w}_{\mathbf{z}}}$ & $\delta \mathbf{c}_{w_{z s}}$ & $\delta \mathbf{c}_{W_{26}}$ \\
\hline When compensation system not engaged & 3.38 & 4.16 & 5.44 & 5.72 & 6.5 & 7.45 \\
\hline When compensation system engaged & 2.25 & 1.85 & 2.40 & 2.92 & 3.71 & 3.92 \\
\hline
\end{tabular}

Table 2. procedure 2 ( ANN prediction results )

\begin{tabular}{|c|c|c|c|c|c|c|}
\hline Step name & $\mathrm{SP}_{\mathbf{x 1}}$ & $\mathrm{SP}_{\mathrm{x} 2}$ & $\mathrm{SP}_{\mathrm{x} 3}$ & $\mathrm{SP}_{\mathrm{x} 4}$ & $\mathrm{SP}_{\mathrm{x} 5}$ & $\mathrm{SP}_{\mathrm{x} 6}$ \\
\hline Depth of Cut $\left(a_{p}\right) / m m$ & 1.00 & 1.50 & 2.00 & 2.50 & 3.00 & 3.50 \\
\hline Error in $\mathbf{X}$ direction & $\delta \mathbf{c}_{\mathbf{w} \mathbf{x}}$ & $\delta \mathbf{c}_{w_{x 2}}$ & $\delta \mathbf{c}_{\mathbf{W}_{\mathbf{3}}}$ & $\delta \mathbf{c}_{\mathbf{w}_{\mathbf{x}}}$ & $\delta \mathbf{c}_{W_{x} s}$ & $\delta c_{W_{x 6}}$ \\
\hline When compensation system not engaged & 3.28 & 4.09 & 4.66 & 7.32 & 8.45 & 8.63 \\
\hline When compensation system engaged & 2.13 & 2.38 & 3.69 & 3.23 & 4.24 & 4.26 \\
\hline Error in $\mathrm{Y}$ direction & $\delta \mathbf{c}_{\mathrm{wy} 1}$ & $\delta c_{w_{y 2}}$ & $\delta \mathbf{c}_{\mathbf{w}, 3}$ & $\delta \mathbf{c}_{\mathrm{w} y 4}$ & $\delta \mathbf{c}_{\mathbf{w y}}$ & $\delta c_{\text {wy }}$ \\
\hline When compensation system not engaged & 3.35 & 4.17 & 4.26 & 5.74 & 6.52 & 6.08 \\
\hline When compensation system engaged & 2.27 & 1.58 & 2.83 & 3.61 & 3.59 & 3.41 \\
\hline Error in $\mathbf{Z}$ direction & $\delta \mathbf{c}_{\mathbf{w z}}$ & $\delta \mathbf{c}_{\mathrm{w}_{22}}$ & $\delta \mathbf{c}_{\mathrm{W}_{23}}$ & $\delta \mathbf{c}_{\mathrm{W}_{\mathbf{z}}}$ & $\delta c_{w_{25}}$ & $\delta c_{W_{26}}$ \\
\hline When compensation system not engaged & 3.54 & 3.47 & 5.92 & 6.46 & 7.44 & 6.75 \\
\hline When compensation system engaged & 2.74 & 1.85 & 2.82 & 3.77 & 2.74 & 3.09 \\
\hline
\end{tabular}

Evaluation procedure 2 (ANN prediction model). In order to test the performance of the ANN model, more prepared test used in the evaluation procedure 1 were used as well. As illustrated in fig.3, the deliberate steps of different height were used to achieve convenient change of depth of cut in a single workpiece mounting.

Similarly, Evaluation procedure was carried out using the same the technical specifications of milling tool and workpiece are as follows:

Workpiece material: Cold Cast steel;

Milling tool diameter (equal to width of milling, $a_{c}$ ) $d_{e}=20 \mathrm{~mm}$;

Milling tool material: Tungsten Carbide $(10 \%$ TC);

Tool angles: rake angle $\gamma_{0}=-5^{0} ; \mathrm{K}_{\mathrm{r}}=60^{\circ}$;

Number of teeth: 4;

Feed per tooth $\left(\mathrm{f}_{\mathrm{z}}\right)=0.16 \mathrm{~mm} / \mathrm{z}$;

Cutting speed $\left(\mathrm{v}_{\mathrm{c}}\right)=63 \mathrm{~m} / \mathrm{min}$.

The ANN prediction model was embedded into the compensator in form of 1 st order polynomial expression. Because of the limitation of the hardware resources of the compensator, the learning process of the ANN remaining is still carried out in the PC MatLab environment. The application of the ANN prediction model as demonstrated yielded improvement to machine error as indicated in table 2 and fig.5.

As well, the two block where inspected by Non-contact Coordinate Measuring Machine (Mututoyo BRIGHTSTRATO 776) for $\mathrm{x}, \mathrm{y}$, and positions.

Whereby $\mathrm{dx}, \mathrm{dy}$ and $\mathrm{dz}$ are workpiece errors without compensation for $\mathrm{x}, \mathrm{y}$ and $\mathrm{z}$ directions respectively; drx, dry and drz are workpiece errors with compensation for $\mathrm{x}, \mathrm{y}$ and $\mathrm{z}$ directions respectively; DoF is the Depth of Cut.

As demonstrated in Fig.5, the ANN prediction model was able to predict the cutting force induced error and help improve the machining accuracy to a great extent. The robustness and flexibility of the ANN model call be improved tremendously by designing a dedicated and compatible hardware to the CNC machine tool. 


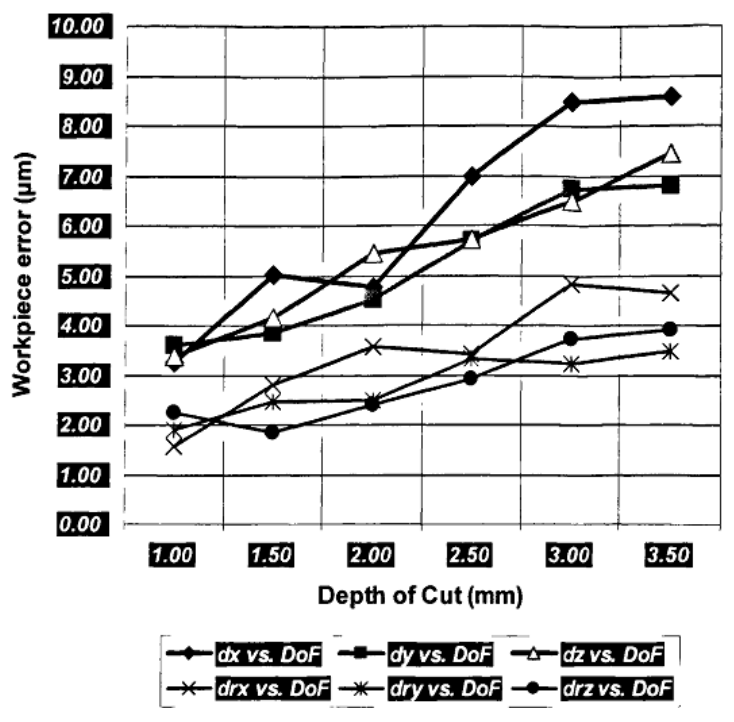

Fig. 4 System Evaluation results for procedure 1

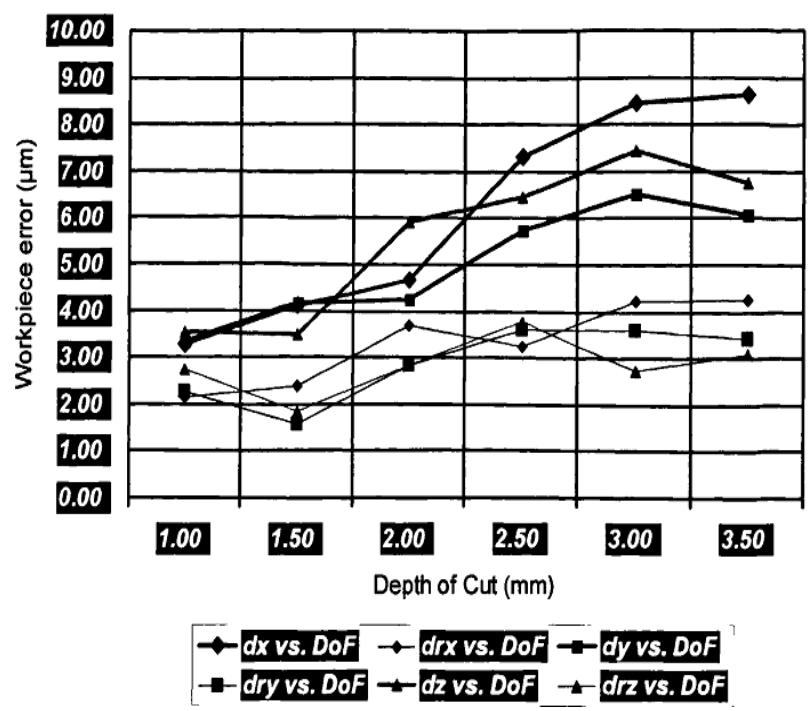

Fig. 5 System Evaluation results for procedure 2

\section{Summary}

(1) The designed of software and hardware systems based on external shifting of machine coordinates origin were used to compensate for CFIE on the VC600 Milling machine.

(2) Evaluation studies that the systems predicted and compensated the CFIE in real-time with precision and reliability.

\section{Acknowledgements}

This project is supported by Science and Technology Fund of Hunan Provincial Science and Technology Department (No.2011GK3090), and 2012 College Research Project of Hunan Industry Polytechnic Grant (No. GYKYZ2012010).

\section{References}

[1] M.S. Hong, H. Su, Comment and strategy of motion accuracy diagnosis of CNC machine tool, J. Mech. Eng. 38 (2002), p.91-94.

[2] H.L. Liu, B. Li, H.M. Shi et al., Embeded-system of position accuracy evaluation and error compensation of CNC machine, J. Huazhong Uni. Sci. Technol. 32 (2004), p.31-33.

[3] X.L. Shen, L.X. Zhang, H.Long and Z.X. Zhou: Appl. Mech. Mater. Vol. 34-35 (2010), p. 1936-1940.

[4] G.L. Samuel and M.S. Shunmugam: Precision Eng. Vol. 24 (2000), p. 251-263.

[5] Jeffrey L. Stein, Kunsoo Huh, Monitoring Cutting Forces In Turning -A Model Based Approach, Transactions of the ASME, Vol. 124 (2002).

[6] X.L. Shen, L.X. Zhang, C.G. Ren and Z.X. Zhou: Adv. Mat. Res. Vols. 97-101 (2010), p. 2053-2057.

[7] Min Xu, Robert B. Jerard, Barry K. Fussell, Energy Based Cutting Force Model Calibration for Milling, Computer-Aided Design\&Applications, Vol. 4 (2007).

[8] X.L. Shen, Y.X. Luo, L.X. Zhang and H. Long: Adv. Mater. Res. Vol. 156-157(2011), p. $1582-1585$.

[9] J.F.G. Oliveira, T.V. Franca and J.P. Wang: CIRP Ann. Vol. 57 (2008), p. 329-332. 